\title{
RANCANG BANGUN ALAT PENGATURAN ARAH PUTAR MOTOR DC POWER WINDOWS BERBASIS PLC PANASONIC MENGGUNAKAN HUMAN MACHINE INTERFACE (HMI)
}

\author{
Tafki Aunika Fariz Alfitri, Iman Setiono \\ Program Studi Diploma III Teknik Elektro \\ Sekolah Vokasi Universitas Diponegoro
}

\begin{abstract}
Tafki Aunika Fariz Alfitri, Iman Setiono, in this paper explain that at this time human life has become more advanced especially in the field of science and technology, all people compete to create technology that is useful and easy for humans. At present the equipment in general has used a remote monitoring and operation system. This system usually uses a microcontroller or PLC as a control. In an effort to facilitate human work, in this case I tried to make a design setting the direction of rotation of the DC power windows. This DC power windows motor is usually used in the car to move the windshield up and down. This Windows power DC motor uses a power supply of 12 volt DC and the output is between 0-5 Volt. This design uses Panasonic PLC as its main control. By using the relay as a reverse rotation setting and forward DC power windows, the motor will automatically move in reverse and forward. The input of a 24 Volt DC panasonic PLC originating from the adapter. The design of this tool can later be applied to a glass in the car by using the Panasonic PLC as its control and other component components needed in the design of the rotary direction arrangement. In the operation by way of toch screen using a human machine interface as a contruction tool to drive the DC power window to spin in reverse or forward
\end{abstract}

Keywords: Panasonic Programmable Logic Controller (PLC), Relay, Human Machine Interface (HMI).

\section{PENDAHULUAN}

Dalam perkembangan zaman yang pesat, semakin banyak tuntutan kehidupan untuk memajukan suatu kinerja yang lebih inovatif dan effisien dalam segala bidang, mulai dalam bidang pendidikan ekonomi, sosial sampai teknologi. Tentunya hal itu menjadi tantangan tersendiri disetiap belahan dunia untuk menemukan ide baru yang bisa di terima oleh masyarakat dan juga dalam dunia industri.

Dalam bidang industri sudah semakin maju dan pesat saat ini semua teknologi baik di industri sekaraang telah memakai sistem pemantau jarak jauh. Dengan sistem pemantau dapat mempermudah pengoprasian peralatan yang digunakan. Dalam hal ini saya membuat rancang bangun pengaturan putaran motor DC power windows. Motor DC power windows biasanya digunakan dalam bidang automotif yaitu dipasang dala kaca mobil.

Rancang bangun alat ini digunakan untuk pengaturan arah putaran pada motor DC power windows yang menggunakan Programmable Logic Controller (PLC) Panasonic sebagai kontrolnya inputan dari PLC berasal dari power supply 24 Volt. Untuk menggerakkan motor dc power windows maka dibutuhkan power supply 12 volt yang akan masuk ke diver dan relay. Pengoprasian rancang bangun pengaturan arah putaran akan di tampilkan dalam HMI.

\section{Power Supply}

Power Supply adalah sebuah perangkat atau sistem yang memasok listrik atau energi ke output yang dihubungkan pada beban atau kelompok beban. Perangkat elektronika mestinya dicatu oleh power supply DC (Direct Current) yang stabil agar dapat bekerja dengan baik. Baterai adalah sumber power supply DC yang paling baik. Namun untuk aplikasi yang membutuhkan daya lebih besar, daya dari baterai tidak mencukupi. Sumber daya yang besar adalah sumber arus bolak-balik AC (Alternating Current) dari PLN.. Secara prinsip rangkaian power supply adalah menurunkan tegangan AC, menyearahkan tegangan AC sehingga menjadi DC, menstabilkan tegangan DC, yang terdiri atas transformator, dioda dan kapasitor/condensator. Tranformator biasanya berbentuk kotak dan terdapat lilitan-lilitan kawat di dalamnya. Tugas dari komponen ini adalah untuk menaikkan atau menurunkan tegangan AC sesuai kebutuhan. Gambar 1 menunjukkan rangkaian adaptor sederhana.

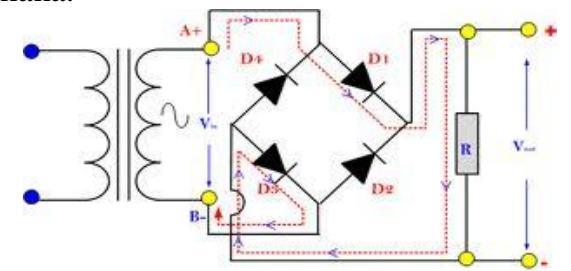

Gambar 1. Rangkaian Adaptor Sederhana

Tegangan jala-jala 220 volt dari listrik PLN diturunkan oleh trafo atau transformator penurun tegangan yang menerapkan perbandingan lilitan. Dimana perbandingan lilitan dari suatu transformator akan mempengaruhi perbandingan 
tegangan yang dihasilkan. Atau dapat dilihat dari persamaan berikut :

$\mathrm{n}=\frac{\mathrm{Np}}{\mathrm{Ns}}=\frac{\mathrm{Vp}}{\mathrm{Vs}}=\underline{\mathrm{Is}}$

Keterangan

$\mathrm{Np}$ : Banyaknya lilitan kumparan sisi primer

Ns : Banyaknya lilitan kumparan sisi sekunder

$\mathrm{Vp}$ : Tegangan sisi primer

Vs : Tegangan sisi sekunder

Ip : Arus sisi primer

Is : Arus sisi sekunder

\section{Programmable Logic Controllers}

Programmable Logic Controllers (PLC) adalah sistem elektronik yang beroperasi secara dijital dan didisain untuk pemakaian di lingkungan industri, dimana sistem ini menggunakan memori yang dapat diprogram untuk penyimpanan secara internal instruksi-instruksi yang mengimplementasikan fungsi-fungsi spesifik seperti logika, urutan, perwaktuan, pencacahan dan operasi aritmatik untuk mengontrol mesin atau proses melalui modul-modul I/O digital maupun analog. Gambar 2 memperlihatkan diagram blok PLC.

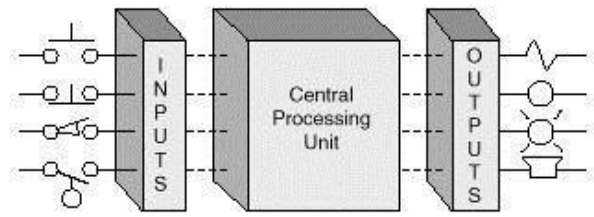

Gambar 2. Blok diagram PLC

\section{Motor DC}

Motor DC atau Motor Arus Searah adalah mesin listrik yang mengubah energi listrik arus searah menjadi energi mekanik.Terdapat 2 (dua) prinsip dasar yang melatar belakangi kerja motor DC. Yang pertama yaitu adanya aliran arus yang melewati sebuah konduktor atau penghantar. Dimana,akan timbul medan magnet mengelilingi penghantar tersebut. Arah garis gaya magnet (fluks magnet) ini sesuai kaidah tangan kiri yang ditunjukan pada gambar 3. Ibu jari menandakan arah arus elektron yang mengalir dan jari-jari menunjukan arah dari garis gaya magnet (fluks) yang mengelilingi penghantar.

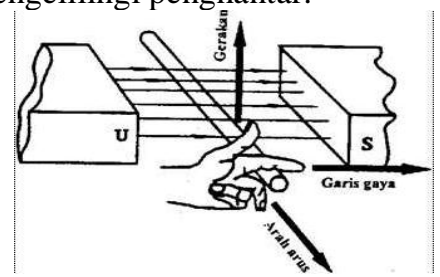

Gambar 3. Kaidah tangan kiri

Yang kedua adalah gaya pada penghantar bergerak dalam medan magnet. Besarnya gaya yang didesakkan untuk menggerakkan peruberubah sebanding dengan kekuatan medan magnet, besarnya arus yang mengalir pada penghantar, dan panjang penghantar.gaya tersebut sering disebut gaya Lorentz. Sesuai dengan rumus:

$$
\mathrm{F}=\mathrm{B} \times \mathrm{I} \times 1 \text { (Newton) }
$$

Dimana:

$\mathrm{F}$ = Gaya padakumparan (Newton)

$\mathrm{B}=$ Kuatmedan magnet (Tesla)

$\mathrm{I}=$ Arus yang mengalir (Ampere)

1 = Panjangkumparan (meter)

Arah dari garis gaya magnet tergantung dari arah arus yang mengalir pada kumparan dan arah dari garis-garis fluks magnet antara dua kutub.

\section{CARA KERJA RANGKAIAN}

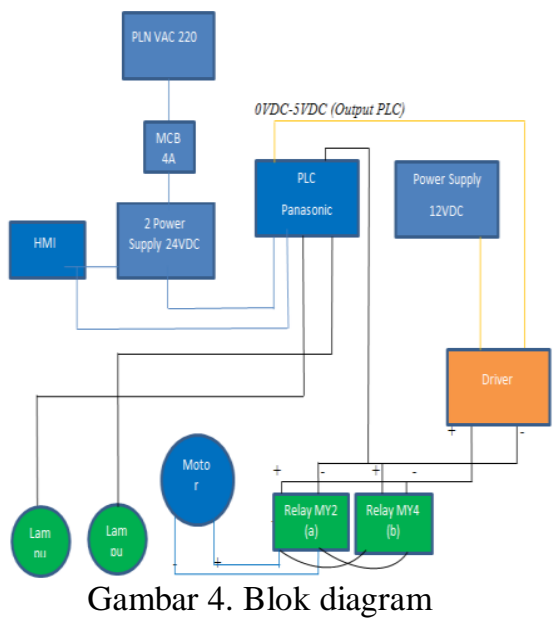

Seperti yang ditunjukkan pada gambar 4, rancang bangun alat ini tegangan input berasal dari PLN sebesar 220 VAC, kemudian tegangan tersebut dijadikan sebagai input tegangan untuk adaptor 24 VDC dan 12 VDC. Adaptor mengubah tegangan AC menjadi DC, kemudian adaptor 24 VDC masuk sebagai tegangan input Programmable Logic Controller (PLC). Output dari PLC akan masuk ke driver motor, Outputan dari driver akan masuk ke relay MY4, relay ini berfungsi untuk mengatur arah putaran motor secara forward dan reverse dengan menggunakan prinsip kutub positif dan kutub negatif relay. Cara pengaturan putaran forward dan reverse diatur dengan menggunakan PLC panasonic. Program utama PLC panasonic menggunakan FPWIN GR. Outputan relay MY4 akan masuk kedalam motor DC power windows 12 volt DC. Untuk menggerakkan motor DC power windows dibutuhkan tegangan 12 volt DC yang diambil dari power supply 12 volt. Outputan dari motor DC adalah sebesar 0-5 volt DC. Dengan prinsisp kutub positif dan kutub negatif relay maka motor DC power windows akan berputar secara forward atau reverse. Kemudian outputan motor akan menuju lampu indikator, lampu ini berfungsi sebagai indikasi apabila motor DC power windows berputar secara forward maka lampu indikator satu akan 
menyala dan apabila motor DC power windows berputar secara reverse maka lampu indikator dua akan menyala. Pemantauan arah puatar motor DC power windows menggunakan human machine interface dengan program utama XP-Build. Pemantauan ini akan menampilkan arah putaran motor DC power windows dan outputan tegangan dari motor DC power windows. Supply daya untuk human machine interface sendiri berasal dari power suplly 24 volt DC. Inputan dari Hmi ini akan masuk ke power supply 24 volt DC sedangkan outputannya akan masuk ke PLC panasonic.

Pada rancang bangun alat pemantau arah putaran motor DC ini menggunakan PLC panasonic sebagai kontrol utama rancang bangun alat ini, masukan dari PLC sebesar 24 volt DC dari supply adaptor 24 volt. Outputan dari PLC berasal dari V0 dan com yang kemudian akan masuk ke driver motor 0-5 volt dan ground. Program PLC menggunakan program FPWIN GR sebagai program utama untuk membuat perintah sehingga PLC dapat berjalan sebagai mana yang kita inginkan. Untuk membuat sebuah program di perlukan Flowchart agar perintah dan logika yang kita buat sesuai dengan yang kita harapkan nantinya. Flowchat program dapat kita lihat seperti pada gambar 5.

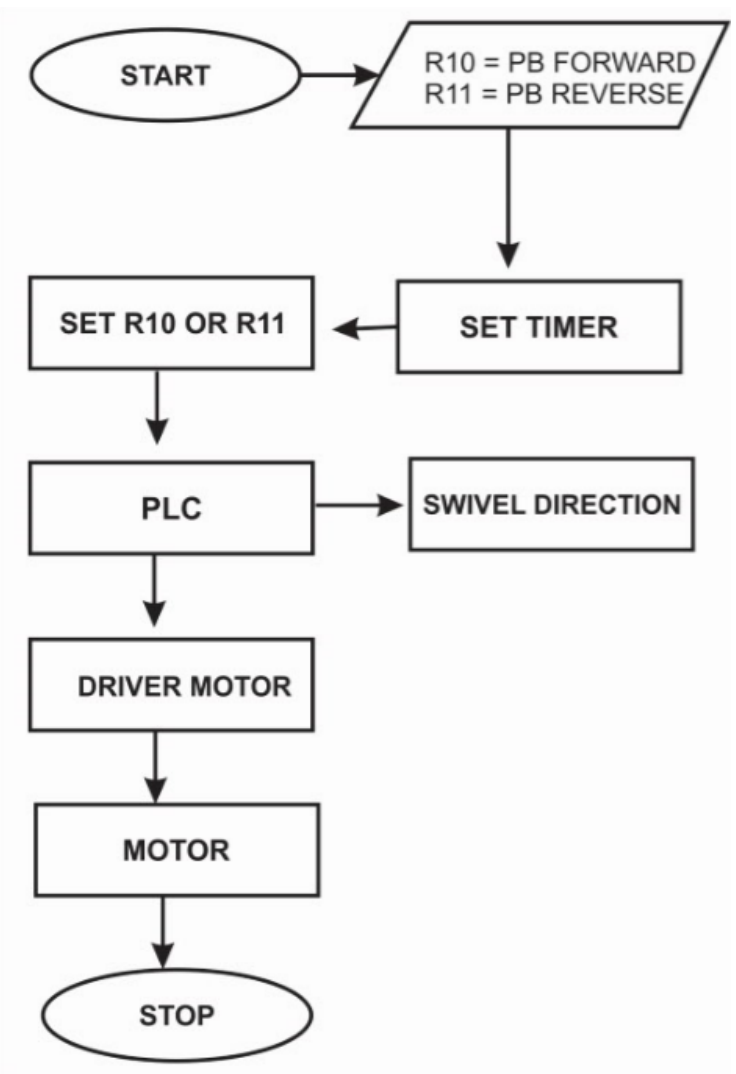

Gambar 5. Flowchart Sistem kerja PLC

\section{PENGUJIAN DAN ANALISA}

a. Rangkaian Catu Daya

Pengukuran rangkaian catu daya pada dasarnya bertujuan untuk mengetahui tegangan keluaran dari rangkaian catu daya agar tegangan keluarannya dapat stabil sebagai catu daya pada masing-masing modul. Pada sistem ini menggunakan rangkaian catu daya dengan tegangan output sebesar 12 Volt dan 24 Volt. Titik pengukuran yang dilakukan meliputi input trafo yaitu dari tegangan jala-jala PLN, output dari trafo yaitu tegangan PLN yang telah diturunkan oleh trafo step down, keluaran dioda sebagai keluaran setelah tegangan disearahkan, output regulator, serta tegangan keluaran akhir. Titik pengukuran ditunjukkan pada gambar 6. Sedangkan hasil pengukuran ditunjukkan pada tabel 1 dan 2.

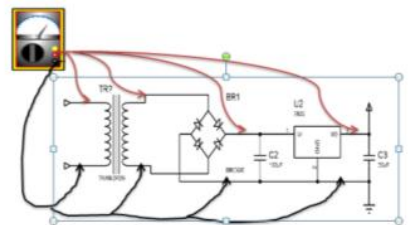

Gambar 6. Titik Pengukuran Catu Daya

Tabel 1. Hasil Pengukuran Catu Daya 12 Volt

\begin{tabular}{clc}
\hline No. & Bagian Yang Diukur & Tegangan \\
\hline 1 & Tegangan Input Trafo & $226 \mathrm{~V}_{\mathrm{AC}}$ \\
2 & Tegangan Output 12 V & $11,8 \mathrm{~V}_{\mathrm{AC}}$ \\
3 & Tegangan Output Bridge & $15,01 \mathrm{~V}_{\mathrm{DC}}$ \\
4 & Tegangan Output & $4,99 \mathrm{~V}_{\mathrm{DC}}$ \\
& Regulator & \\
\hline
\end{tabular}

Tabel 2. Hasil Pengukuran Catu Daya 24 Volt

\begin{tabular}{clc}
\hline No. & Bagian Yang Diukur & Tegangan \\
\hline 1 & Tegangan Input Trafo & $226 \mathrm{~V}_{\mathrm{AC}}$ \\
2 & Tegangan Output $24 \mathrm{~V}$ & $23,9 \mathrm{~V}_{\mathrm{AC}}$ \\
3 & Tegangan Output Bridge & $28,01 \mathrm{~V}_{\mathrm{DC}}$ \\
4 & Tegangan Output & $7,69 \mathrm{~V}_{\mathrm{DC}}$ \\
& Regulator & \\
\hline
\end{tabular}

b. Relay

Pengukuan relay pada dasarnya digunakan untuk mengetahui tegangan inputan dan outputan dari relay sehingga kita dapat mengetahui apakah relay dapat bekerja dengan baik atau tidak. Hasil pengukuran relay ditunjukkan pada tabel 3 dan 4 .

Tabel 3. Hasil Pengukuran relay MY4N

\begin{tabular}{clc}
\hline No. & Bagian Yang Diukur & Tegangan \\
\hline 1 & Tegangan Input relay & $24 \mathrm{~V}_{\mathrm{AC}}$ \\
2 & Tegangan Output relay & $23,9 \mathrm{~V}_{\mathrm{AC}}$ \\
\hline
\end{tabular}

Tabel 4. Pengukuran Keseluruhan

\begin{tabular}{ccccc}
\hline No. & Tegangan & Timer & $\begin{array}{c}\text { Reverse/ } \\
\text { Forward }\end{array}$ & Ket \\
\hline 1 & 5,98 Volt & 1 & $\checkmark$ & $1 / 8$ \\
2 & 5,98 Volt & 2 & $\checkmark$ & $2 / 8$ \\
3 & 5,98 Volt & 3 & $\checkmark$ & $3 / 8$ \\
4 & 5,98 Volt & 4 & $\checkmark$ & $4 / 8$ \\
5 & 5,98 Volt & 5 & $\checkmark$ & $5 / 8$ \\
6 & 5,98 Volt & 6 & $\checkmark$ & $6 / 8$ \\
7 & 5,98 Volt & 7 & $\checkmark$ & $7 / 8$ \\
8 & 5,98 Volt & 8 & $\checkmark$ & $8 / 8$ \\
\hline
\end{tabular}


Analisa Hasil dari pengujian yang telah dilakukan sebelumnya pada alat ini adalah Alat tersebut dapat bekerja mangatur arah putaran motor DC power windows dengan menggunakan relay MY4N untuk mengatur arah putaran secara reverse ataupun forward dengan menggunakan HMI. Alat ini juga dapat diatur secara otomatis menggunakan HMI dengan cara di set dengan HMI dengan skala 060 second.

\section{KESIMPULAN}

Adapun beberapa kesimpulan yang diperoleh sebagai berikut :

- Prinsip kerja alat ini menggunakan prinsip dasar relay untuk mengatur arah putaran motor secara forward dan reverse

- Rancang bangun alat pengaturan arah putaran motor DC power windows ini berhasil dibuat dan bekerja sesuai perencanaan awal yaitu menggunakan kutub positif dan negatif medan magnet untuk mengatur putaran secara forward dan reverse dan kemudian di tampilkan dalam HMI.

- Sistem pengaturan forward dan reverse menggunakan HMI sebagai pengaturannya dengan menggunakan program FPWIN GR PLC panasonic yang di catu oleh adaptor 24 Volt

- Saat motor berputar ke arah forward dan reverse maka lampu indikator berwarna hijau akan menyala

\section{DAFTAR PUSTAKA}

1. Andrik, Rizki. Kontrol Arah dan Kecepatan Motor DC Menggunakan Android. http://library.um.ac.id. (diakses pada 20 Juni 2017, pukul 20.15)

2. Utomo, Joko. Rancang Bangun Pengendali Dan Monitoring Motor DC Menggunakan Komputer Berbasis Mikrokontroller. http://digilib.unila.ac.id. (diakses pada 16 Juni 2017, pukul 19.30).

3. Hart, Daniel W. 2011. Power Electronics. Singapore: Mc Graw Hill.

4. Raharjo, dkk. 2005. Teori Dasar Elektronika dan Mengenal Komponen Elektronika. Departemen Pendidikan Nasional : Jakarta

5. Gônen, Turan. 1988. Modern Power Sistem Analisis. Amerika Serikat: CRC Press

6. Kusuma, Arya. Pengertian Programmable Logic Control (PLC) dan Jenis-Jenis PLC. kusumawarya.blogspot.co.id. (diakses pada 29 Mei 2017, pukul 19.30)

7. Abenk. Prinsip kerja PLC. http://www.insinyoer.com/prinsip-kerja-plc programmable-logic-controller/. (diakses pada 30 Mei 2017, pukul 07.00)
8. Herman, Stephen. 2005. Understanding Motor Controls. New York : delmar cengage learning

9. Apyanti, Riska. PWM. http://riskaapyanti.blogspot.co.id.(diakses pada 2 Juni 2017, pukul 09.30)

10. Kho, Dickson. Pengertian Relay dan Fungsinya. www.teknikelektronika.com. (diakses pada 30 Mei 2017, pukul 09.15)

11. Sukamdani, Yunus . Motor DC Power Window. Www.yunusarisumpurworejo powerwindow.blogspot.co.id. (diakses pada 26 Mei 2017, pukul 20.15)

12. Rudy. HMI. http://xbrey.blogspot.co.id. (diakses pada 1 Juni 2017, pukul 20.00) 